\title{
Tales of Emergence-Synthetic Biology as a Scientific Community in the Making
}

\author{
Susan Molyneux-Hodgson \\ Department of Sociological Studies, University of Sheffield
}

Morgan Meyer

Centre de Sociologie de l'Innovation, MINES ParisTech

\begin{abstract}
This article locates the beginnings of a synthetic biology network and thereby probes the formation of a potential disciplinary community. We consider the ways that ideas of community are mobilized, both by scientists and policy-makers in building an agenda for new forms of knowledge work, and by social scientists as an analytical device to understand new formations for knowledge production. As participants in, and analysts of, a network in synthetic biology, we describe our current understanding of synthetic biology by telling four tales of community making. The first tale tells of the mobilization of synthetic biology within a European context. The second tale describes the approach to synthetic biology community formation in the UK. The third narrates the creation of an institutionally based, funded 'network in synthetic biology'. The final tale de-localizes community-making efforts by focussing on 'devices' that make communities. In tying together these tales, our analysis suggests that the potential community can be understood in terms of 'movements'the (re)orientation and enrolment of people, stories, disciplines and policies; and of 'stickiness' - the objects and glues that begin to bind together the various constitutive elements of community.
\end{abstract}

Keywords: Community-making Devices, Emergence, Identity, Scientific Communities, Synthetic Biology 
Interest in the area of synthetic biology is growing rapidly. Indeed, this article is a contribution to the ongoing debate in this journal about the emerging field (Anonymous, 2008; Calvert, 2008; Lentzos et al., 2008; Pottage, 2006). The funding announcement in early 2008 from the BBSRC (the UK Biotechnology and Biological Sciences Research Council) of the establishment of seven networks in synthetic biology (NSBs), followed by the publication of a report on ethical and social aspects of synthetic biology (Balmer and Martin, 2008), appear to us to mark a symbolic starting point for synthetic biology in the UK context.

At an international level, the 4th synthetic biology conference took place in Hong Kong in October 2008 and articles on synthetic biology have been appearing in journals such as Nature and Nature Review Genetics (e.g. Benner and Sismour, 2005; Endy, 2005). The current situation prefaces what appears to be a long-term research agenda for scientists and social scientists alike. Ongoing work on the reproduction of scientific communities (Hodgson, 2006; Molyneux-Hodgson and Facer, 2003), and on the practices and boundaries of communities (Meyer, 2007, 2008) has led to our current interest in the emergence of a potential community of synthetic biology practitioners. Synthetic biology is a prominent contender for the next 'promissory science' (Hedgecoe, 2003): a promising area of science, that has the right 'label', that puts forward visions and is able to attract support. Leaving aside what the science may or may not deliver in the future, our focus here is on the work already under way to establish synthetic biology as a field. In particular, we wish to focus on how the formation of a synthetic biology community is being accomplished.

At the same time, we too are explicitly members of this emergent community due to the inclusion of so-called ELSI researchers (those that study Ethical, Legal, and Social Issues or Implications) in the NSBs that form part of the UK's approach to synthetic biology development. While we are uncomfortable with the ELSI label, we nevertheless need to situate ourselves in relation to the emerging field and a specific NSB, and so this article also represents an attempt to grasp our own location in the emerging field. Synthetic biology presents us, as sociologists of science, with an opportunity to engage with scientists involved in an emergent area of scientific practice and with the possibility of tracing the process of community building in actu (in 'real time'). Our article is structured as follows. We first review some of the ways in which scientific communities have been conceptualized previously and note the scarcity of work on 'beginnings' found within the field of social studies of science. Then, we will present four tales of emergence which give partial insights to the generation of the current situation. The first tale recounts how synthetic biology has materialized in the European Union (EU) over the past few years and some of the policy work involved in this process. Following this, tale two will explore how synthetic biology is forming in the UK context and the work that led to a call for, and establishment of, NSBs. Our third tale is about the creation of one such network, based at a UK university. Having traced through these tales the emergence of synthetic biology from a 'global' to a 'local' level, in our fourth tale we then look at how a sense of a universal, collective enterprise is recreated through what we term 'community-making devices', that is, entities such as journals, postdocs, conferences and success stories. 


\section{Theorizing scientific communities and their emergence}

It is commonplace in the social studies of science, as well as other disciplines, to argue that scientists are not isolated individuals who work on their own but that they 'do things together' (see Becker, 1986). They are part of a collective of people who share forms of language, sets of theories, technologies, and so forth. In brief, scientists are part of a community. Over the years, sociologists of science have come to examine scientific communities through various theoretical approaches (see Dubois, 1999 for a review): they have been understood as a 'normative' unit (Merton), as 'invisible colleges' (Crane), as 'thought collectives' (Fleck), as a 'paradigmatic' unit (Kuhn) and, more recently, as something more akin to 'transactional' units (e.g. Bourdieu; Latour and Woolgar; Hagstrom). As social studies of science began to leave behind the norms and the ethos of science as the focus of their study, sociology increasingly explored scientific communities 'in action' (Latour, 1987), looking at the practices and the cultures of science (Pickering, 1992). Scientific communities were not only organized around the things that they knew, but also around the way they worked together. The alleged unity of science was increasingly put under question, while its multiplicity and disunity became emphasized (Dupre, 1993; Galison and Stump, 1996; Knorr-Cetina, 1999). Alongside, there has been a shift from analysing communities as self-referential organizations and as merely concerned with scientific knowledge, to an understanding of scientific communities as more heterogeneous assemblages that cut across the public and the private, the social and the technical, nature and culture, and so forth. Indeed, increasingly we see these 'scientific' networks cut across and incorporate social science and humanities disciplines and concerns. Recent theorizing has also seen communities of scientists intrinsically as 'communities of promise'. 'Within communities of promise, expectations structure and organize a whole network of mutually binding obligations between innovators, investors, consumers, regulators and so on' (Brown, 2003: 6).

Scientists are, in this sense, members of 'communities of hope' since their present actions are shaped by an imagined future. Central to understanding scientific communities is the need to consider how they reproduce and change over time. In particular we need to consider what processes are involved, what kinds of events, social formations and political conditions, may lead to new communities emerging. Mody (2006) has described the interactions between instrument development and various interested groups in the evolution of nanotechnologies. Gingras (1991) has explicitly focused on aspects of emergence in his consideration of physics as a case in Canada. He offers an analytical model for examining the formation of identifiable communities, a process that he describes along three overlapping dimensions: emergence, institutionalization and the creation of a clear social identity (1991: 4-6). The first phase consists of the development of a research practice, either through the importation of know-how or through the reconstruction of individual trajectories which have yet to be institutionalized. Then, after the conditions for the generation of research practice have been established, individual and institutional identities are aligned: we see the institutionalization of research, a crucial step in the formation of a scientific community. Gingras writes:

It is, in effect, the condition for the growth and survival of a community, for only by setting up institutional structures which favour the production of knowledge 
and the reproduction of agents endowed with the necessary dispositions for this activity can scientists reproduce themselves as a group and participate in activities that constitute a scientific field. (1991: 5)

The third step consists in the formation of a social identity, be it disciplinary or professional (e.g. 'physicist'). So, Gingras lays out potential ways in which we could track the genesis of a synthetic biology community. However, his work considered the development of a community at the beginnings of the twentieth century and, while emphasizing the production and reproduction of community and the means through which institutionalization can be accomplished (departments, curricula, funding, scholarships, etc.), Gingras did not consider the external forces shaping this emergence (Conway, 1992). Nor did he offer any concepts to describe the structures and conditions that come before community. Hence, we need to give further thought to conceptualizing the emergence of synthetic biology as a collective activity. In particular, we should be mindful of the potential multiplicity of approaches that the term 'synthetic biology' encompasses (O'Malley et al., 2007) and the range of possible communities that could emerge.

\section{Locating an emerging community}

To conceptualize an emerging community, and begin to study empirically the processes involved, we need to tie the genesis into ongoing, broad movements occurring at many levels beyond our location within a UK synthetic biology network. Fujimura (2000) has argued, using the case of translational genomics, that national context is significant in that such context changes the production of knowledge in biology in important ways. Thus our study of the way in which a potential scientific discipline emerges needs to maintain a sense of place, as evolving structures depend on local and national contingencies (Collins and Pontikakis, 2006). The emergence of a community of practices is not a global process (even though it can be made to become a global process).

Although the study of laboratory science from ethnographic perspectives is well established, usually the laboratories to study and the communities that occupy them already exist, whereas our initial interest is rooted in what happens prior to the establishment of physical working spaces and fixed identities of occupants. Thus, in order to examine the emergence of synthetic biology we need to look to a variety of places where community can be made and articulated. We propose considering devices as mundane as a workshop and a grant funding proposal, and things as 'high brow' as an EU policy document and a UK policy initiative as equally relevant. In other words, we aim to be symmetrical in our approach (Callon, 1986) and not a priori concerned whether the factors that shape communities are local or global, texts or talks, bottom-up or top-down, internal or external. We start with the assumption that all these are entwined in the emergence of scientific communities and that each needs to be taken into (our) account.

The empirical materials we will draw upon for this article include: transcripts of interviews with lead participants in the local NSB; policy documents, reports and statements from scientific institutions in the UK; research documents; and reflective diaries of the two authors based on attendance at meetings, seminars and workshops from mid-September 2007 onwards. In this sense, we are undertaking a 
multi-sited ethnography (Marcus, 1998: 79), an ethnography that 'moves out from the single sites and local situations of conventional ethnographic research designs to examine the circulation of cultural meanings, objects, and identities in diffuse timespace'. Given that our main concern is in 'how'-How does a community appear to materialize, become global, become 'textured'? How is a community 'heterogeneously engineered' (see Law, 1986)? - we want to find a way to talk about scientific communities that is neither too general, and thus unable to focus on practices and contents, nor too narrowly focused on a single field site and blind to what takes place beyond this site (Vinck, 1999: 390). To start this project then, we will recount four tales of emergence that present a 'snapshot' of the story of synthetic biology so far.

\section{Tale one: mobilizing synthetic biology in Europe}

On entering the 'field' of synthetic biology, we found the need to look East (to Brussels) and West (to the US), and to the past eight years, to locate some origins of community. The last eight years can be identified as seeing important developments in terms of policy work around the notion of convergence, that is, the idea of the bringing and coming together of different scientific fields. A particular US research and technology policy initiative from 2001 is often cited as the starting point for discussions about the idea of converging technologies. This initiative, shortened to $\mathrm{NBIC}$, aims to bring together the fields of nanotechnology, biotechnology, information and communication technologies and the cognitive sciences in order to 'improve' human performance (Roco and Bainbridge, 2003). Despite reservations from various quarters, and the strong military focus of the original initiative, it had an important impact on the European Commission. In response to NBIC, the European Commission has developed its own approach titled 'Converging Technologies for the European Knowledge Society' (CTEKS), which aims to be a more demand driven approach in which converging technologies respond to societal needs and demands.

Initiatives like NBIC and CTEKS present optimistic futures and a range of utopian promises. New terms come to the fore in these policy statements, blurring the boundaries between technology and nature, inanimate and animate-terms such as 'nanobiotechnology', 'synthetic biology', and 'new bionics'. These terms can be taken as signs of the spreading of NBIC-type convergences (Coenen, 2008: 61). So let us now turn specifically to policy work in the domain of synthetic biology, which was identified as one of eight key areas of convergence in the EU policy arena (Andler et al., 2007). In 2005, the EU NEST (New and Emerging Science and Technology) programme published a report entitled Synthetic Biology-Applying Engineering to Biology. The report states that:

Synthetic biology is a nascent field, and there is currently no systematic, global effort to coordinate the developments in this field. [. . .] What is needed [. . .] is a framework for coordinating the current research, fostering a community of researchers (particularly among young researchers) and creating a forum for the establishment of clear goals, shared tools and agreed standards. (European Communities, 2005: 7, emphasis added) 
The report further asserted that what was needed was funding, intellectual and physical infrastructures, education and training activities, conferences, and human resources - 'synthetic biology is a young discipline that needs some nurturing to flourish' (European Communities, 2005: 20). In addition to the NEST report, the 'Towards a European Strategy for Synthetic Biology' initiative was launched, which had as its core a series of workshops, and also the EMERGENCE initiative, which aims 'to provide a communication and working platform for the emerging European synthetic biology community in order to strengthen the organizational and conceptual basis of synthetic biology as a true engineering discipline in biological engineering' (http://www.emergence.ethz.ch/home.htm, emphasis added; see also Greener, 2008). The European vision for synthetic biology involves using the science to resolve 'societal challenges'; for example, finding replacements for fossil fuels; developing novel medical diagnostics, and microbial approaches to cleaning water. Incited by these reports and initiatives, and perhaps the perceived leadership of the US in synthetic biology developments-and the consequent risks of 'lagging behind'-things started to happen in the UK national context. As one of the principal investigators of an NSB described the situation:

the UK has seen that this field is starting to grow [. . .] that it could be something that's important for UK science, UK industry, UK plc, however you want to describe it. And so they've decided [. . . ] to put money in to get people to work together to see what the field should be and how to shape the field and how to get to various end points. (R1)

An integral part of 'what the field should be' is a coming together of existing communities; not just from large, amorphous areas of science (like nanotechnology and ICT) as suggested by convergence-speak, but also specific, named disciplines. The Royal Society (2007: 1) writes: 'Synthetic biology has developed from the convergence of knowledge and tools from other disciplines.' The field of synthetic biology is conceived as drawing on various disciplines: molecular biology, engineering, physics, computer modelling, etc. and so specific administrative techniques are needed to bring about the meeting of the communities involved. Commenting on the launch of the UK networks, the Minister for Science and Innovation lan Pearson stated:

By developing this emerging science, the UK will continue to keep its leading edge. [...] This initiative [the NSBs] is aimed at raising UK profile and capability in this area to put the country at the forefront of the field. (in BBSRC, 2008a)

While this story is clearly a partial one, we see here evidence of a policy accomplishment process (Hodgson and Irving, 2007). Synthetic biology, as a strategic policy object and an arena in which it is allegedly important not to 'fall further behind' (both for the EU and the UK) has been translated into concrete communitybuilding efforts. The resources needed to build communities and do scientific research-funding, training, communications support, networks, etc.- are being made available or are in development. As Vinck has argued (1999: 391), the creation of scientific networks has now become subject to political drives to organize scientific work. What we also see is the carving out of areas of interest and potential research focus; in part to differentiate the European synthetic biology project from other 
versions. There is a concurrent bringing together of existing communities and a differentiation and filtering of research activity, to guide the emerging community.

\section{Tale two: building capacity in the UK}

In the UK, funding bodies have shown an increasing interest in synthetic biology (Lentzos et al., 2008: 312): two research councils currently 'signpost' it as a key area of funding interest and several specific committees are dealing with issues relating to this field. The BBSRC has an Engineering and Biological Systems committee and a Biomolecular Science committee that cover relevant issues. Both committees have standing arrangements with the EPSRC (the UK's Engineering and Physical Sciences Research Council) for co-funding if appropriate. And it is via its Bioscience for Society panel, that the BBSRC considers social and ethical issues within its remit. The BBSRC states that it was 'giving serious consideration to the potential ethical, moral and societal impacts' of synthetic biology and a working group had been set up to explore the area (resulting in the 2008 Balmer and Martin report). Within the EPSRC, synthetic biology has emerged as an important area for development in the Engineering Directorate. Several routes to getting support for synthetic biology projects are being made available, e.g. workshops, research projects, student bursaries for iGEM (the International Genetically Engineered Machines competition). Finally, synthetic biology has also been on the agenda in discussions within the Royal Society, the Royal Academy of Engineering and the Royal Society of Chemistry (Lentzos et al., 2008: 311). Institutional awareness of the emerging science and support for its development appears widespread, even concerted.

In 2006, the BBSRC established a working group on synthetic biology in order to reflect on the important issues that may arise in the field and on how to shape future research. An outcome of the recommendations of this working group was the organization of a Synthetic Biology Workshop which took place in February 2007. The workshop aimed to: 'assist in the development of an interdisciplinary synthetic biology research community'; identify 'community-support needs' and to devise research programme agendas (BBSRC, 2007: n.p.). The workshop brought together researchers from a variety of disciplines as well as representatives from several other research councils. '[I]t was agreed that building a community was vital',(1) and that this was deemed necessary due to the perceived large gap between the disciplines involved. Ideas generated by the workshop participants, in order to build this community, included: using generic methods for new community development such as 'sand-pits';(2) the funding of networks to enable the 'forging of multi-disciplinary collaborations'; using discipline-hopping schemes to enable 'fostering (of) disciplinary cohesion'; feasibility studies and grant applications that would follow from networks.

There was debate at the workshop over whether a fixed definition for synthetic biology was needed or not. Some participants viewed synthetic biology as not a new science, but rather as an 'extension of what has already been done', an extension of existing biotechnology (similar arguments to this appear in the field of nanotechnology, see Pottage, 2006: 144). Other participants were keener on 
establishing sameness, continuity, a seamless change. The participants expressed the need for care in defining synthetic biology in the sense of how much work already existed in this area. Interestingly, one of the keynote speakers said in his abstract that he had used 'a form of synthetic biology'-i.e. undertaken a series of steps to cut, paste and manipulate at the genomic level, to create a specific form of an organism, from which other things were done. Questions over whether current practice is, or is not, synthetic biology, have yet to be resolved.

The seemingly mundane task of defining a field and settling on a name is a difficult exercise, that is, definitional arguments point to something interesting. It has been argued that the 'process of naming also sets in place the concept of borders to a community' (Molyneux-Hodgson and Facer, 2003: 156). Naming something 'synthetic biology' is not an innocent exercise, for it delimits, renders more visible, more powerful, and increases the potential to attract funding for, certain forms of work. Further, naming creates an order (see Hetherington, 1997: 191); to designate scientists as synthetic biologists produces a homogeneous and bounded discursive space.

Yet, while participants at the workshop expressed the need for synthetic biology to 'mature', including defining the area and bringing together the disciplines, it was also stressed that 'Research Councils should be careful to avoid premature "professionalization" of this area. [. . .] If a thematic programme were launched, it would be important not to be restrictive or prescriptive, since synthetic biology was still developing.' The workshop report further stated: 'there was agreement that a thematic programme/research initiative was premature, for synthetic biology, at this stage, in the UK'. Hence, while there was a perceived need to discursively stabilize synthetic biology, and to find a common vocabulary and bounded arena of operation, there was also resistance towards rigidifying it too far. Part of the reticence regarding a specified research programme appears to arise from a desire to let things emerge from the ground-perhaps programmes are seen as too prescriptive, and, as synthetic biology is still developing, it requires research that includes 'bottom-up approaches'. While this tale can be understood as part of larger debates on the balance of funding for research between 'top-down' governmental initiatives and 'bottom-up' or 'blue-skies' scientist-driven work, it is also suggestive of the notion of 'interpretive flexibility' (Pinch and Bijker, 1992) that describes the multiple, culturally constructed understandings of phenomena.

Networks in synthetic biology.

Following from this workshop, a joint call for proposals or NSBs was issued by the BBSRC and the EPSRC later in 2007 (additional partners being the AHRC [Arts and Humanities Research Council] and the ESRC [Economic and Social Science Research Council]). The aims of the networks included: developing and establishing communication and networking, forming partnerships, and building 'a cohesive, cross-disciplinary community' in synthetic biology (BBSRC, 2007: n.p.). The call was framed to include ethics and stressed the need to handle 'social and natural issues' concurrently.

The call for networks prompted scientists from various universities in the UK to put together proposals and apply for funding. A requirement of the funding stream was the inclusion of ELSI researchers, indeed additional material was requested from these participants as part of the funding decision making process, whereby ELSI 
workers had to specifically state their objectives for participation in the networks.(3) Seven network projects were eventually successful. The networks were announced in a press release given by the BBSRC in June 2008 in which it was stated that the networks should 'allow UK researchers [. . .] to form a true synthetic biology community' (BBSRC, 2008b: n.p.).

\section{Tale three: making a synthetic biology network}

When the call came out for network proposals, I thought that this is something that the university ought to do. (R2)

A scientist and an engineer from one university had attended the BBSRC workshop in 2007. When the call for networks was posted by the BBSRC, the two academics first called on collaborators from their existing projects-mostly projects on 'systems biology'- and recalled the work of other researchers in the university to generate ideas towards a proposal. Brainstorming sessions and meetings were held and draft documents were circulated.

I gazed at a sheet of paper for a while. [. . . I thought that it would be rather interesting to be able to synthesize the kinds of molecules that are of use in the tissue engineering field. [. . . ] l'd heard X [a name] give a talk, so I just went to see $X$ and spoke to her and some of her colleagues [. . .] we decided more or less there and then that this would be worth trying. (R2)

In the final network proposal, tissue engineering-and specifically 'making glues in microbes' (R2) - is put forward as a potential key area in which future research might take place, claiming that synthetic biology: 'will have major benefits for providing materials for tissue engineering, stem cell therapies and regenerative medicine, both with replacing current therapies and developing new ones not possible with current technology' (M.A., 2007: 1). Yet, like other NSBs funded by the BBSRC, the focus is not on research per se but on creating networks, a fact that the proposal repeats 'This is a network to develop ideas, not a research project' (M.A., 2007: 1, underlined in original). 'The aim is to generate more debate and drive the field forward' (ELSI text from proposal).

In the proposal, apart from a discussion about the specific area of scientific research envisaged in the future, a lot of text is devoted to research management matters. For instance:

The overall objective [. . .] is to build, within 3 years, a Network with the critical mass and skills-set necessary to tackle this challenging project in synthetic biology and thereby allow the network to become self-sustaining and contribute to new technologies and materials derived from breakthroughs in the synbio field. (M.A., 2007: 1) 
Consequently, the outcome and success of the network is not to be measured in terms of direct research outputs, but in terms of infrastructural achievements and proposals for future work: 'We will know we have succeeded in the network's overall goal if a significant proposal or set of proposals in applying synthetic biology to biomaterials problems arises [. . .] and a formal centre has been created' (M.A., 2007: 6, emphasis added). Apart from articulating a number of visions and setting out promises, the proposal is notable for its emphasis on the structure of the network, which has to be sustained, developed, formalized. The kind of network being described in the proposal resembles what have been called 'forums'. Vinck (1999: 394), who distinguishes five forms of networks, defines forums as:

networks [that] organise the exchange of ideas and the constitution of a community of interest. They lead to the emergence of cooperation [. . .] and to the structuration of a collective problem. The most important intermediary objects here are of a textual nature (invitations, programmes, conference proceedings).

Over time, Vinck argues, forums will evolve into different kinds of networks that become increasingly structured, productive and stable. At the time of writing this article the local network is organizing a kick-off retreat to 'officially' begin operation, but it already does exist and operates in various ways: it has been funded, it has brought together a range of people who agreed to work together, it has been written down, it has a draft website-i.e. it has been 'inscribed' in multiple forms. The participants in the network are materialized in a table at the end of the proposal, a table that contains a list of people and partners, including their affiliations and research interests. The proposal further lists activities such as inviting 'key' international visitors, travel to conferences and the organizing of an international meeting.

\section{Identity-work}

It is important, at this point, to stress that something is also absent from the proposal and the other inscriptions outlined above: missing, are scientists who are 'synthetic biologists'. While there is some evidence in the literature for scientists naming themselves 'synthetic biologists', or as is more often the case, being labelled by others as such, this is primarily done in relation to long-established disciplinary communities. For example, two key papers describing the character of synthetic biology by scientists working in the area, Endy (2005), and Benner and Sismour (2005) draw explicit links between the existing collectives of biological engineering and chemistry, respectively, and the future activity of synthetic biologists. Indeed in 2005 Benner and Sismour already classified synthetic biologists as coming in two broad classes, separated by their end goals and means of achieving them.

In our interviews we have asked questions about existing community affiliations and disciplinary identities of the people involved in the synthetic biology network. As one of the principal investigators explained:

it's like a Venn diagram. [. . .] Some people are obviously members of a synthetic biology community, but they may also be members of a molecular biology community and so there is some sort of intersection between communities. (R1)

This quotation is suggestive of a transition period for individual scientists. We have asked individual investigators how they describe themselves. Responses include: 
Oh l'm a microbiologist. [. . .] My own research is very much on the interface of biochemistry and microbiology. So a lot of my academic life has been spent in biochemistry departments. [. . .] This is more or less a biochemistry department we're in now, although it doesn't quite have that name. But, I was trained as a microbiologist, so that's how I normally identify myself. (R2)

I think the broadest term that I describe myself is probably a bio-chemical engineer. I probably don't describe myself as a synthetic biologist [but] if you ask me the same question in five years time, I might. (R1)

My main community of reference is the bio-informatics systems biology community. A synthetic biology community [. . . ]? I don't think that exists yet. (R3)

In the NSB, the people who do synthetic biology do not describe themselves as synthetic biologists. Yet, as the second quotation reveals, this is potentially due to change. The network proposal suggested that there may be 'new lecturer posts [. . . ] to be picked up by the university beyond the terms of the grant. One of these is earmarked as a synthetic biology lectureship' (M.A., 2007: 4, underlined in original). Evident here is a sense of identity that is an ongoing project; that still needs to be negotiated and further institutionalized. The difference between a synthetic biologist and, say, a microbiologist is, at the current time, one of identity as 'becoming' rather than identity as 'being' (see Simpson and Carroll, 2008: 31). All of the respondents above were already working together on systems biology projects prior to the synthetic biology network funding, so they are concurrently holding links to disciplines, research collectives and multiple fields of interest. The fluidity of identity within the network clearly requires further analysis and is beyond the scope of the current article. However, it seems apparent that the network will perform an important role in structuring the emerging synthetic biology community at a localized scale.

The ongoing identity work brings us back to the beginning of our first tale of mobilizing synthetic biology on an EU level, where the lack of synthetic biologists is portrayed as follows: 'in the long term it would be desirable to create a new breed of researchers who are familiar both with fundamental biology and with the methodology of engineering, as well as having requisite skills in areas such as computational sciences and chemistry' (European Communities, 2005: 7). What is particular about this 'new breed of researchers' in terms of identity formation? We see a bringing together of knowledge from various domains; this new 'breed' is described and positioned as being an identity in-between other, already existing identities. At the same time, this identity is on a trajectory, that is, the articulation of identity is based on two elements: imagination and alignment-the envisioning of possible futures and the doing what it takes to get there (Wenger, 2000: 241).

\section{Tale four: creating a sense of a global collective}

In the tales above, we have encountered a number of devices that we will call here 'community- making devices'. Policy initiatives, workshops, calls for proposals and networks are all devices that help make, or at least articulate the need for, community. While occasioning community-building effort, the tales are dominated by movements of various kinds, e.g. shifts in individual definitions of belonging; the seeping of policy from macro to micro locales; (the) reorientation of resources, etc. 
Also, the devices we have described so far are attached to specific arenas: the EU, the UK, the university. In what follows, we want to discuss briefly a few 'communitymaking devices' that are less bound to distinct spaces and are less about movement than providing 'glue' to capture and begin to sustain emerging links.

First, there are events and associations. One example is the annual, worldwide International Genetically Engineered Machines (iGEM) competition that primarily involves undergraduate students in synthetic biology, the first of which took place in 2004. The aim is to engineer biological devices using a library of standardized parts (called BioBricks) made available to the students entering the competition. On the iGEM's website we find 'community news', the annual competitions are called 'jamborees'. One association is http://syntheticbiology.org which also includes a 'Community News' section, with the first news item dating back to 1 November 2002. It includes: calls for conferences, workshops, competitions; information about the launch of new journals or new publications; declarations; lectures; information about mailing lists. Second, there are new journals being set up. IET Synthetic Biology, first issued in 2007, states that it 'will aim to support this growing new community. [. . . In particular, we wish to support the activities of young workers entering the synthetic biology field.' Another journal is Systems and Synthetic Biology: 'a new biomedical journal to publish original papers and articles on all aspects of Systems and Synthetic Biology'. The participants of the local NSB currently express ambivalence towards these journals:

There are some journals that are starting to emerge, but obviously they're quite new so time will tell as to whether they're successful and people do support them by publishing directly in there or still go for the, maybe the highimpact [journals]. (R1)

It's too early to, to say [. . . ] the top systems biology and synthetic biology results are not published in those journals, they are published in Nature or Science, Cell, Plant Biology, or, you know, these high-impact factor journals. (R3)

The ambiguity about these journals can be taken as a sign of emergence. They have not yet become, not yet stabilized, into key 'community outlets'. This uncertainty is in stark contrast to the major conference in the field. Synthetic Biology 1.0, the first international meeting on synthetic biology-the 'inaugural' conference (European Communities, 2005: 19) - took place in 2004 in the US (Cambridge, Massachusetts). The 2008 meeting, the fourth one of its kind, took place in Hong Kong. One of the investigators in the NSB described this conference as:

A proper recognized international meeting now. It's been in the United States and now it's been in Europe and [. . .] it's in Asia next year. [. . .] several hundred people go to it, it has got an official name, and it's moving between continents now, so that does give it [. . . ] a stronger international foundation as a real emerging discipline. (R1, emphasis added)

In general, conferences are one of the traditional channels-alongside journals-for scientific dissemination of knowledge (Lamb and Davidson, 2005). The international synthetic biology conference is a far more prominent and visible forum than the journals just mentioned. It has attracted an increasing number of participants and 
takes place in different locations across the globe. It produces stickiness through being able to bring together the main players in the field.(4) It has become, in other words, a knowledge maker (Collins, 2006), an institutionalized space where findings are communicated and knowledge is exchanged, and, above all, where identities can be shaped.

Finally, synthetic biology has its prominent success story: the development of a cheap anti-malaria drug through creating a new bacterial strain able to produce amorphadiene. This story is omnipresent in the material we have analysed: it has been mentioned by the people we interviewed; it is referred to in reports, in articles, etc. While current work in the sociology of expectations and communities of promise rightly stresses the role of visions, hypes and futures, we want to press the point that the past is also mobilized in important ways when constructing the future. In particular, it is through (re)telling 'success stories' (i.e. the anti-malaria drug) that the past becomes enrolled as a sort of guarantor for future developments in synthetic biology. It has been argued elsewhere that: 'Scientists need stories to support their work - stories they tell to funding bodies, governments, venture capitalists and the general public. Without the right story, their research cannot survive' (Anonymous, 2008: 12). Success stories have the further advantage that, unlike heavy equipment, they can travel faster and without much (financial) cost. A success story like the antimalaria drug thus has several functions: it travels within the community and thereby strengthens its interconnectedness, it becomes part of the shared repertoire of that community giving it a sense and purpose, and it enables future work (see also Felt, 1993).(5) Even though this particular success story has highly localized origins (a research team at the University of California, Berkeley headed by scientist Jay Keasling) it has already become a rather global story, a widely shared memory of a whole (and still emerging) community.

The devices described above have in common not only that they shape an emerging community of practice with a 'shared repertoire of communal resources-language, routines, sensibilities, artifacts, tools, stories, styles, etc.' (Wenger, 2000: 229, emphasis in original); but they act as initial sticking points in that they are also able to 'bring together the collective' (Latour, 2004) in particular ways; they provide opportunities to do community within the melee of shifts and movements that are required to create a space for a potential new community.

\section{Discussion}

So far, we have presented four tales: a tale about the mobilization of synthetic biology as a project within Europe; a tale about capacity building in the UK; a tale of the creation of a synthetic biology network at an institutional level; and promotion of a sense of global, collective endeavour. There are, of course, more tales that could be told about synthetic biology: tales about the creation of research groups or departments, tales about the relationship between synthetic biology and other disciplines, tales about instruments and techniques, 
tales about regulation, tales that begin in different places, tales about 'embedded' sociologists, tales about emerging and changing metaphors,(6) and so on and so forth. So there are, on the one hand, more stories to be told and more aspects of synthetic biology that future research needs to explore. On the other hand, there are interconnections between the tales we have just told.

The tales we have presented operate at multiple levels. Alongside the narratives of the development of the science, are tales of community building, of the emergence of the scientists who will do the old/new science. Here, we have identified techniques of community building at different levels and that operate in different ways (including discursive, institutional, financial, etc.).

Overall, our aim was to map out the terrain of synthetic biology as we see it from our own institutional position within a network, as an initial step in understanding how to locate ourselves as members of an emergent synthetic biology community and toward the generation of a set of research questions for our ongoing study of an NSB in the UK. Toward this end, we sense the need to move beyond Collins and Evans' notion of 'interactional expertise' (2007) towards notions of legitimate peripheral participation (Lave and Wenger, 1991); whereby our engagement within the NSB perhaps allows us to both 'represent and intervene' (Hacking, 1983) in scientific knowledge production. Reflecting on the role of social scientists in synthetic biology, Calvert and Martin (2009) propose a distinction between the role of the contributor, an ELSI expert 'plugged in' after natural scientists have produced scientific knowledge, and that of the collaborator, who can genuinely influence and interact with knowledge production. We would tend toward the latter orientation but would further stress that our relationship with synthetic biology mirrors that of the identitiesin-the-making we have described above: it is a relationship in the making; it is uncertain, ambiguous and currently being negotiated; and we have yet to stabilize our roles and positions in relation to other identities. We believe that emerging communities can be analysed through identifying the mixture of movement and stickiness. A variety of movements have come to the fore: scientists getting enrolled, disciplines converging (in policy, if not yet practice), the mobilization of resources (such as money, equipment, etc.).

These movements consist, in other words, of the movements of the building blocks of a community and the convergence of these towards some central position. Such movements create a more or less homogeneous space in which it is possible, safe and fruitful to work together. Other movements are also visible: building upon past 'success stories', articulating future promises and expectations, using linguistic tools to emphasize a trajectory ('building', 'emergence', etc.). These more temporal movements are pointing towards a future state: the community itself is seemingly on a trajectory to evolve into a state that is more stable, better defined, more visible and, above all, able to deliver at least some of the promises. Apart from these movements, an emerging community is also trying to stop certain things from moving, to lock some entities into a fixed position. This has become evident through the perceived needs to develop a shared vocabulary, a common language, the efforts to clarify, to agree . . . in other words, to stabilize. 
In order to create 'stickiness', emerging communities of scientists tap into a repertoire of existing 'community-making devices'. Associations and events, conferences, journals and success stories are, we argue, such markers and makers of community. These devices help to create a sense of a global collective of people and practices enrolled in the project of synthetic biology. Like other, established communities that use these devices to reproduce their community, emerging communities use these to establish themselves, to create an initial sense of community, to create a visible, demarcated and powerful niche. In doing so, they use devices and ideas which are both ubiquitous - a sort of 'ideal type'-and are specifically shaped to meet the particular needs of their community. In addition to these, we would also argue that discourses of emergence and newness are significant structuring devices-used by social scientists and scientists alike-and not so dissimilar from the communitymaking devices just mentioned. These discourses about emergence enrol people, establish links and create a sense of community. They have an effect on the way scientists align their practices with other scientists. Perhaps what an emerging community lacks in history and foundations is compensated for through discourses about emergence that provide a sense of direction and future, and by getting people interested in a project. At the same time, much discussion and, above all, uncertainty about the definition of synthetic biology is evident in these early days - which, we can already surmise, will become black-boxed and taken for granted in the future.

\section{Summary}

Our work in this article has been to make a first attempt at articulating the early stages of a potential community in the making and to contribute to a growing body of work on synthetic biology. We aimed to elaborate some of the ways in which ideas of 'community' are being mobilized in the synthetic biology project across different scales and places. Our intent was to capture something of the complexity and multifaceted nature of the origins of a potential synthetic biology community.

We have proposed two key organizing ideas as a means of understanding the emergence of the field; namely 'movement' and 'stickiness'. These notions are intended to capture some of the fluidity of the process of scientific change, in opposition to long-standing narratives of the progress of science that emphasize a more linear, progressive story, and as an alternative to studies of communities that are already fixed.

In tracing the emergence from our position of association with a funded network in synthetic biology, we follow Sarah Franklin's invocation to 'begin with the specific and the localised' when addressing the large questions relating to processes of scientific change (Anonymous, 2008: 13). A key question, of course, is the extent to which what we see happening from our position is something 'new'; hence our use of the term 'emergence', in order to temper the sense of radicality and dislocation that can often be detected in debates between social scientists and natural scientists. It remains to be seen whether 'synthetic biology' will become a separate discipline with a delineated community of practitioners, a sub-field of one of its constituent parents, or segue into some other configuration. 


\section{Acknowledgements}

We would like to thank participants in one of the BBSRC-funded Network in Synthetic Biology events for their cooperation, in particular our interview respondents R1, R2 and R3. Thanks also to Dave Phillips for his comments on an earlier draft and to three anonymous referees.

\section{References}

Andler, D., Barthelme, S., Beckert, B., Blumel, C., Coenen, C., Fleischer, T. et al. (2007). 'Converging technologies' and the social sciences and humanities-An analysis of critical issues and a suggestion for a future research agenda. Final Report. Fraunhofer Institute for Systems and Innovation, Unpublished.

Anonymous (2008). Beyond the genome: The challenge of synthetic biology. BioSocieties, 3(1), 3-20.

Balmer, A., \& Herreman, C. (2009). Craig Venter and the re-programming of life: How metaphors shape and perform ethical discourses in the media presentation of synthetic biology. In B. Nerlich, R. Elliott, \& B. Larson

Elliott, R., \& Larson, B. (Eds), Communicating biological sciences: Ethical and metaphorical dimensions, 219-234. London: Ashgate.

Balmer, A., \& Martin, P. (2008). Synthetic biology: Social and ethical challenges. Institute for Science and Society, University of Nottingham.

BBSRC (2007). Synthetic biology workshop. Report of a workshop at Alexandra House, Wroughton, Wiltshire, 8-9 February, unpublished.

BBSRC (2008a) Synthetic Biology Networks launch document. URL (accessed April 2009): http://www.bbsrc.ac.uk/publications/corporate/synthetic_biology.pdf

BBSRC (2008b). New projects to raise UK profile in Synthetic Biology, press release, 29 May, URL (accessed October 2008): http://www.bbsrc.ac.uk/media/releases/2008/080529_synthetic_biology.html

Becker, H. (1986). Doing things together: Selected papers. Evanston, IL: Northwestern UP.

Benner, S.A., \& Sismour, A.M. (2005). Synthetic biology. Nature Review Genetics, 6, July, 533-543.

Brown, N. (2003). Hope against hype: Accountability in biopasts, presents and futures. Science Studies, 16(2), 3-21.

Callon, M. (1986). Some elements of a sociology of translation: Domestication of the scallops and the fishermen of Saint Brieuc Bay. In J. Law (Ed.), Power, action and belief: A new sociology of knowledge, 196-233. London: Routledge.

Calvert, J. (2008). The commodification of emergence: Systems biology, synthetic biology and intellectual property. BioSocieties, 3, 383-398.

Calvert, J., \& Martin, P. (2009). The role of social scientists in synthetic biology. EMBO Reports, 10, 201-204.

Coenen, C. (2008). Konvergierende Technologien und Wissenschaften. Der Stand der Debatte und politischen Aktivitaeten zu 'Converging Technologies'. Hintergrundpapier Nr. 16. Berlin: TAB.

Collins, H.M. (2006). Conferences as knowledge makers. Paper presented at the 45 conference 'Silence, Suffering and Survival', Vancouver, 1-5 November.

Collins, H.M., \& Evans, R.J. (2007). Rethinking expertise. Chicago: U Chicago Press.

Collins, P., \& Pontikakis, D. (2006). Innovation systems in the European periphery: The policy approaches of Ireland and Greece. Science and Public Policy, 33, 757-769.

Conway, J.F. (1992). Physics and the rise of scientific research in Canada by Yves Gingras. Canadian Journal of Sociology, 17, 224-226.

Dubois, M. (1999). Introduction à la sociologie des sciences et des connaissances scientifiques. Paris: Presses Universitaires de France.

Dupre, J. (1993). The disorder of things: Metaphysical foundations of the disunity of science. Cambridge, MA: Harvard UP.

Endy, D. (2005). Foundations for engineering biology. Nature, 438, 24 November, 449-453.

European Communities (2005) Synthetic biology: Applying engineering to biology. Report of a NEST high-level expert group. Luxembourg: European Communities.

Felt, U. (1993). Fabricating scientific success stories. Public Understanding of Science, 2, 375-390.

Fujimura, J.H. (2000). Transnational genomics in Japan: Transgressing the boundary between the 'modern/West' and the 'premodern/East'. In R. Reid, \& S. Traweek (Eds), Cultural Studies of Science, Technology, and Medicine, 71-92. New York: Routledge.

Galison, P.L., \& Stump, D.J. (1996). The disunity of science: Boundaries, contexts, and power. Palo Alto, CA: Stanford UP.

Gingras, Y. (1991). Physics and the rise of scientific research in Canada, trans. P. Keating. Montreal: McGill-Queen's UP.

Greener, M. (2008). Is the grass greener on the other side? Encouraging the development of synthetic biology in Europe. EMBO Reports, 9, 835-837.

Hacking, I. (1983). Representing and intervening-Introductory topics in the philosophy of natural science. Cambridge: Cambridge UP.

Hedgecoe, A.M. (2003). Terminology and the construction of scientific disciplines: The case of pharmacogenomics. Science, Technology \& Human Values, 28, 513-537.

Hetherington, K. (1997). In place of geometry: The materiality of place. In K. Hetherington, \& R. Munro (Eds), Ideas of difference: Social spaces and the labour of division, 183-199. Oxford: Blackwell.

Hodgson, S.M. (2006). Narrating community: History and absence in scientific texts. Interdisciplinary Science Reviews, 31, 175188.

Hodgson, S.M., \& Irving, Z. (2007). Policy and its exploration. In S. Hodgson, \& Z. Irving (Eds.), Policy reconsidered: Meanings, politics and practices, 1-18, Bristol: Policy Press.

Knorr-Cetina, K. (1999). Epistemic cultures: How the sciences make knowledge. Cambridge, MA: Harvard UP.

Lamb, R., \& Davidson, E. (2005). Information and communication technology challenges to scientific professional identity. The Information Society, 21, 1-24.

Latour, B. (1987). Science in action: How to follow scientists and engineers through society. Cambridge, MA: Harvard UP. 
Latour, B. (2004). Politics of nature: How to bring the sciences into democracy. Cambridge, MA: Harvard UP.

Lave, J., \& Wenger, E. (1991). Situated learning: Legitimate peripheral participation. Cambridge: Cambridge UP.

Law, J. (1986). On the methods of long distance control: Vessels, navigation and the Portuguese route to India. In J. Law (Ed.), Power, action and belief: A new sociology of knowledge, 234-263. London: Routledge \& Kegan Paul.

Lentzos, F., Bennett, G., Boeke, J., Endy, D., \& Rabinow, P. (2008). Visions and challenges in redesigning life. BioSocieties, 3 , 311-323.

M.A. (multiple authors) (2007). Unpublished network proposal to BBSRC.

Marcus, G.E. (1998). Ethnography through thick and thin. Princeton: Princeton UP.

Meyer, M. (2008). On the boundaries and partial connections between amateurs and professionals. Museum and Society, 6 , 38-53.

Meyer, M. (2007). Increasing the frame: Interdisciplinarity, transdisciplinarity and representativity. Interdisciplinary Science Reviews, 32, 203-212.

Mody, C.M. (2006). Corporations, universities, and instrumental communities: Commercializing probe microscopy, $1981-1996$. Technology and Culture, 47, 56-80.

Molyneux-Hodgson, S., \& Facer, K. (2003). The textbook as cultural artefact: Reproducing the culture of science. In R. Sutherland, G. Claxton, \& A. Pollard (Eds.), Learning and teaching: Where worldviews meet, 153-74. Stoke: Trentham.

O'Malley, M.A., Powell, A., Davies, J.F., \& Calvert, J. (2007) Knowledge-making distinctions in synthetic biology, BioEssays, 30(19): 57-65.

Pickering, A. (Ed.) (1992). Science as practice and culture. London: U Chicago Press.

Pinch, T., \& Bijker, W. (1992). The social construction of facts and artifacts: or, How the sociology of science and the sociology of technology might benefit each other. In W. Bijker, \& J. Law (Eds.), Shaping technology/building society, 17-50. Cambridge, MA: MIT Press.

Pottage, A. (2006). Too much ownership: Bio-prospecting in the age of synthetic biology. BioSocieties, 1, $137-158$.

Roco, M.C., \& Bainbridge, W.S. (Eds.) (2003). Converging technologies for improving human performance: Nanotechnology, biotechnology, information technology and cognitive science. Dordrecht: Kluwer Academic Press.

Royal Society (2007) Call for views: Synthetic biology, June. URL (accessed May 2009): http://royalsociety.org/downloaddoc.asp?id1/44297

Simpson, B., \& Carroll, B. (2008). Re-viewing 'role' in processes of identity construction. Organization, 15, $29-50$.

Vinck, D. (1999). Les objets intermédiaires dans les réseaux de coopération scientifique. Contribution à la prise en compte des objets dans les dynamiques sociales. Revue française de sociologie, 40, 385-414.

Wenger, E. (2000). Communities of practice and social learning systems. Organization, 7, 225-246.

\section{Notes}

(1) All the quotations in this section are from the unpaged workshop report (BBSRC, 2007).

(2) Sand-pits are a kind of 'close encounter' and brainstorming approach -the rationale being that if you put people in close proximity to each other, and structure their activity over an intense period of time, you will generate a collective vision and/or agenda and/or project.

(3) Perhaps this is a key difference between synthetic biology and other communities: the fact that the social sciences are posited as not only a legitimate but also a constitutive element of the community. This 'upstream' involvement of social scientists is commonly explained by the need to avoid controversies such as those around genetically modified organisms. Hence, it seems to us that, like other emerging communities, the synthetic biology community mobilizes hopes, expectations and promises, but unlike other communities, it has to a certain degree internalized a prominent fear and is thus institutionalizing and policing the involvement of social science in a rather novel way.

(4) Also worthy of being mentioned is the first synbiosafe conference, an e-conference which lasted about a month and focused on the ethical, safety, public, etc. issues arising with synthetic biology.

(5) Felt (1993: 375) lists six ingredients allowing the construction of a scientific success story: "political and economic interest; the flair of "little" science; the presence of hero scientists; the possibility of staging an international

(6) Some authors have argued that 'metaphors begin to emerge, it seems, quite specifically in order to provide suitable analogies for the representation of the inner workings of synthetic biology' (Balmer and Herreman, 2009: 221) and that there is a shift from literary metaphors (i.e. 'the book of life') to computational metaphors (2009: 231). 